\section{Noticias y comentarios}
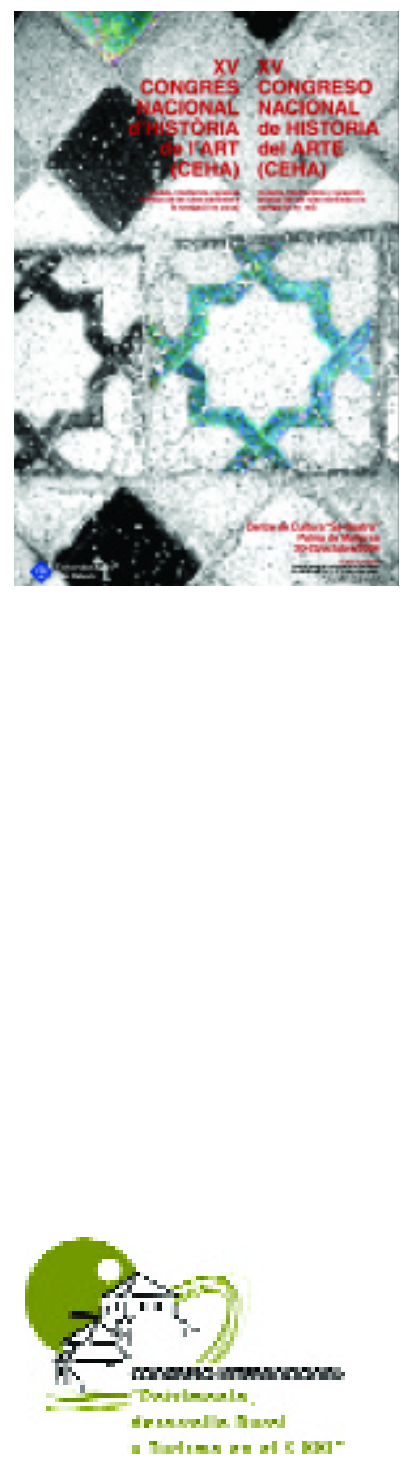

Logo del foro internacional

\title{
La escasa reflexión sobre turismo y patrimonio, entre las conclusiones del último congreso del CEHA
}

Siguiendo la filosofía del Comité Español de Historia del Arte, se celebró del 20 al 23 de octubre de 2004 en Palma de Mallorca el XV Congreso de Historia del Arte. Bajo el título Modelos, intercambios y recepción artística (de las rutas marítimas a la navegación en red), el congreso se articuló a partir de una serie de mesas, que fueron introducidas por distintas ponencias:

$>$ Arte hispano de los siglos VI-XI. Recreación o viaje de las formas.

> Fuentes gráficas y literarias: incidentes en el desarrollo artístico de la Edad Moderna.

> Introducción a la investigación histórico-artística. $>$ Turismo y patrimonio.

$>$ Comercio y difusión del arte en España en el siglo XIX.

Aparte, hay que destacar la realización de un Forum sobre la situación de la Historia del Arte en el marco del Espacio Europeo de Educación Superior.

La Sección sobre Patrimonio y turismo cultural fue acogida con gran interés, a juzgar por el elevado número de comunicaciones que concurrieron. En lo que atañe a los enfoques expuestos y debatidos, las conclusiones a extraer son las siguientes:

$>$ Escasa reflexión teórica sobre la relación turismo y patrimonio.
$>$ En oposición, el dominio fue para la explicación de ejemplos concretos desde una perspectiva histórica y a nivel de protección, de rehabilitación y de reconversión de uso o destino, planteada bien a nivel monográfico (Hospital de Santiago; San Juan de la Peña), bien a nivel general, como la cuestión de los conjuntos arqueológicos.

> Insistencia en la difusión del patrimonio, enfocando y sistematizando las vías pertinentes, desde los itinerarios didácticos hasta el papel de los medios no personales.

$>$ Hincapié en la potenciación de modalidades poco difundidas dentro del patrimonio cultural, caso de los sitios históricos, de las casas - museo y del jardín histórico; del mismo modo, estudiar manifestaciones escasamente atendidas, caso de los graffiti o del patrimonio industrial.

> Análisis del papel del patrimonio como dinamizador cultural y económico.

$>$ Especial atención a la necesidad de ofrecer, a través del patrimonio, una alternativa al turismo de masas, un turismo de sol y playa.

$>$ Consideración de los peligros que encierra la oferta cultural patrimonial: el espectáculo y la banalización.

Catalina Cantarellas

Presidenta del XV Congreso

\section{Se inicia un foro de debate para contribuir a la sostenibilidad de espacios rurales y urbanos}

Durante los pasados días 20, 21 y 22 de octubre de 2004, Osuna (Sevilla) acogió la celebración del I Congreso Internacional sobre Patrimonio, Desarrollo Rural y Turismo en el Siglo XXI, por iniciativa de la Escuela Universitaria Francisco Maldonado de Osuna, dentro del marco del V Centenario fundacional de la Hispalense.

El principal objetivo del evento fue iniciar un foro de debate de ámbito internacional, como máximo de periodicidad bianual, en el que se expongan posibles líneas de mejora en las ciudades a través de las áreas de patrimonio, desarrollo rural y turismo.

En el congreso han participado más de 200 académicos y profesionales de más de 40 instituciones nacionales e internacionales. En el área de patrimonio se presentaron un total de 30 trabajos de investigación sobre campos muy diversos.
El área de desarrollo rural contó con, 14 trabajos orientados a la mejora del medioambiente, gestión del paisaje rural, mejora de los equipamientos, etc. Turismo constituyó el área que acogió a un mayor número de ponencias, un total de 34 , siendo diversos los campos que se abordaron, tanto en el ámbito público como privado, aunque todos presentaron un nexo común: la mejora del turismo y su gestión como antecedente para el incremento de la demanda de turistas en el contexto de los espacios urbanos y rurales.

Texto completo de las ponencias del Congreso: Web: www.euosuna.org

Antonio Navarro García

Secretario del Congreso 